Ayla Sayli

Ahmet Dursun Alkan

Merve Aydin

http://dx.doi.org/10.21278/brod67401

\title{
DETERMINATION OF RELATIONAL CLASSIFICATION AMONG HULL FORM PARAMETERS AND SHIP MOTIONS PERFORMANCE FOR A SET OF SMALL VESSELS
}

UDC 629.5.015.2:629.5017.2:629.52

Preliminary communication

\begin{abstract}
Data science for engineers is the most recent research area which suggests to analyse large data sets in order to find data analytics and use them for better designing and modelling. Ship design practice reveals that conceptual ship design is critically important for a successful basic design. Conceptual ship design needs to identify the true set of design variables influencing vessel performance and costs to define the best possible basic design by the use of performance prediction model. This model can be constructed by design engineers. The main idea of this paper comes from this crucial idea to determine relational classification of a set of small vessels using their hull form parameters and performance characteristics defined by transfer functions of heave and pitch motions and of absolute vertical acceleration, by our in-house software application based on K-Means algorithm from data mining. This application is implemented in the C\# programming language on Microsoft SQL Server database. We also use the Elbow method to estimate the true number of clusters for K-Means algorithm. The computational results show that the considered set of small vessels can be clustered in three categories according to their functional relations of their hull form parameters and transfer functions considering all cases of three loading conditions, seven ship speeds as non-dimensional Froude numbers $(F n)$ and nine wave-length to ship-length values $(\lambda / L)$.
\end{abstract}

Keywords: Conceptual ship design; Data Mining; Clustering; K-Means, Database; C\# 


\section{INTRODUCTION}

A product life cycle of the system analysis and design in the domains including Marine Systems can be seen in two phases such as "Acquisition Phase" and "Utilization Phase". It can be seen from Fig. 1 that "Conceptual Design Stage (CDS)" is the first part of the acquisition phase, and then the following part is called "Preliminary Design Stage". CDS has been defined in several sub-parts which are shown in Fig. 2. The nature of ship design offers complex and interactive data evaluations under dynamic and also iterative environment with a large number of relational and conflicting parameters. Ship design practice reveals that conceptual ship design is critically important for a successful conclusion of Preliminary Design stage and thus basic design. CDS constitutes the most delicate design stage among the other stages since the critical assumptions and decisions can be made. The greatest impact on ship's overall economic efficiency is made during the conceptual design stage. Conceptual ship design accounts more than 80 percent of the ship value, hence an optimal design has a great impact in ship whole life cycle [1,2]. Conceptual ship design needs to identify true set of design variables influencing vessel performance resulting successful building of performance prediction model on the way of defining best possible conceptual design. In the present paper, we focused on a part of seakeeping ability of ships surrounded by response amplitude operators (RAO) of vertical ship motions. The status of CDS requires knowledge-based approaches since human ability is limited to extract relations among the data concerning design variables and performance values. The literature offers several studies of knowledge-based and expert systems applied to conceptual ship design, however the studies on data mining utilization are quite limited. Chen and Yao [3] studied an analysis on ship equipment consumption data using clustering technique of data mining. Their data mining procedure used massive ship maintenance support data and concluded that an effective classification of equipment consumptions yields important references for guarantee department. Li et al. [4] applied data mining technique to ship virtual assembly based on rough theory. Li et al. gave gains of data mining model in terms of reducing dependence on operational experience of human-being and increasing ship assembly efficiency. Mosavi [5] introduced LADTree algorithm, a classification type of data mining, to analyse the effect of each design variable to given objectives. Mosavi reported that number variables for the optimization diminished in the example of airfoil form optimization. Mosavi also claims that the classification based data mining is able to speed up optimization procedures and simplify Multiple Objective Optimization and Multiple Objective Decision Making systems.

The main idea of this paper comes from this crucial idea to determine relational classification of a set of small vessels using their hull form parameters and performance characteristics defined by transfer functions of heave and pitch motions and of absolute vertical acceleration, by our in-house software application based on K-Means algorithm from data mining. The computational results show that the considered set of the vessels can be clustered in three categories according to their functional relations of their hull form parameters and transfer functions considering all cases of three loading conditions, seven ship speeds as nondimensional Froude numbers (Fn) and nine wave-length to ship-length values $(\lambda / \mathrm{L})$.

The amount of data is increasing very quickly due to the very fast development of information technology. The data stored in databases is worthless alone. It is difficult to find interesting and valuable information in very large databases. Valuable information can be accessed by analysing the data through various statistical methods. Data mining is the process of finding significant and unknown knowledge in data. Clustering is an unsupervised learning technique for grouping similar data points from data mining techniques. Cluster analysis is based on finding information that clusters are objects of groups according to their relationships. 


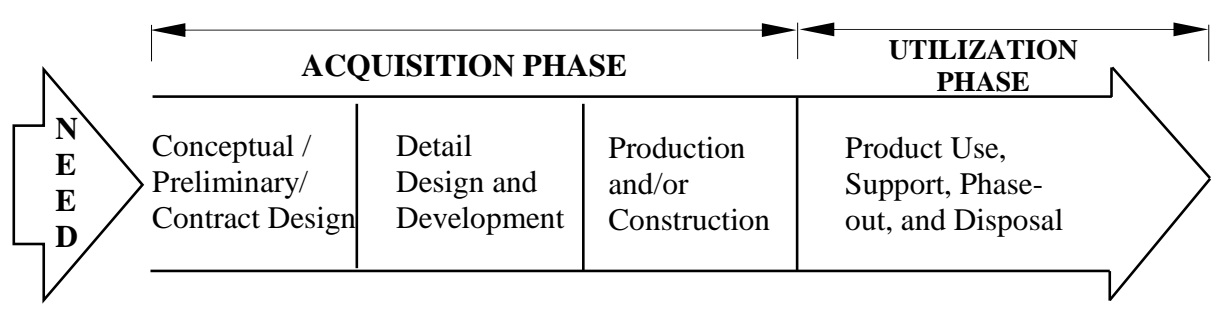

Fig. 1. Product Life Cycle.

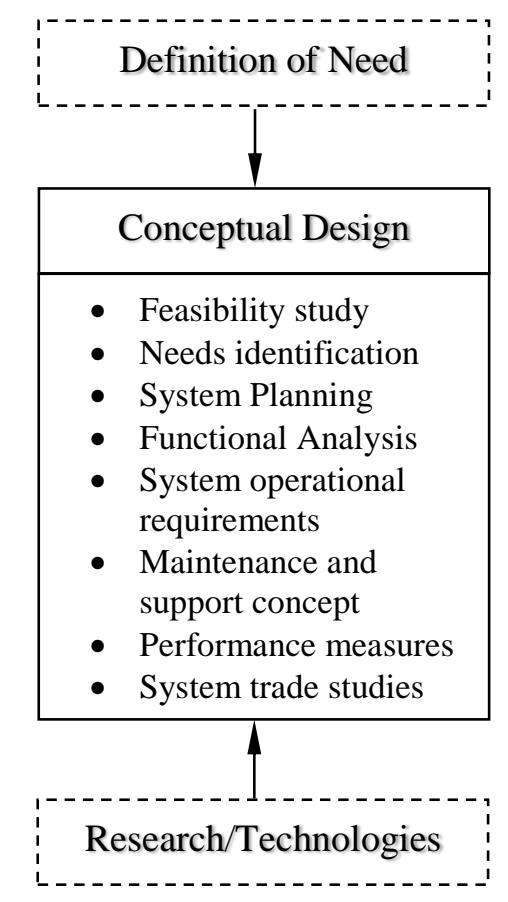

Fig. 2. Sub-Parts of Conceptual Design Stage.

The K-means algorithm is the most widely used clustering algorithm. This algorithm partitions a data set into k groups according to similarity. An integer $\mathrm{k}$ for a set of small vessel data of $\mathrm{n}$ data points in $\mathrm{N}$-dimensional space is called the cluster number. The center of the cluster is average of points in this cluster. K-means aims to minimize SSE (Sum of Squared Error). Selecting particular value of $\mathrm{k}$ is important for correct clustering. The Elbow method is used for the determination of the true number of $\mathrm{k}[6,7]$.

In Section 2, our vessel database composed of ship size and hull form parameters are explained. K-Means algorithm for data mining is introduced in Section 3. Section 4 gives information on our in-house software application for K-means algorithm with the Elbow method and its interface. Section 5 contains computational results of the analyses which are carried out for vessel clustering to remark outstanding consequents of clusters for seakeeping. The last section summarizes conclusions and future work of this study. As concluded, cluster analysis will be useful to seek and judge significant set of design parameters influencing various outputs of interest that enables the naval architect to develop robust and innovative solutions based on scientific approaches. 


\section{VESSEL DATABASE}

Mediterranean fishing vessel data set has values of hull form parameters of the lines plans for a set of each fishing vessel. The hull form parameters of the lines plans are geometric variables of each fishing vessel. The body plans of the vessels are shown in Fig. 3. Each fishing vessel has been evaluated at three different loading conditions: LC1-leaving to the fishing ground (100\% consumables), LC2-leaving from the fishing ground (full holds and $40 \%$ consumables) and LC3-arrival to port (full holds and 10\% consumables). The set of fishing vessels are shown in Table 1. Each three rows in Table 1 is values of the same fishing vessel at three loading conditions. In addition, this data set has motions of vessels in terms of RAOs of Heave, Pitch and Vertical Absolute Acceleration at stern. The RAO computations have been carried out by means of a two-dimensional computer code based on Frank close-fit method [8, 9]. The values of motions are based on Froude numbers and $\lambda / \mathrm{L}$ values at loading conditions. Froude numbers are $0.00,0.05,0.10,0.15,0.20,0.25$ and $3.00 . \lambda / \mathrm{L}$ values are $0.50,0.75,1.00$, $1.25,1.50,1.75,2.00,2.50$ and 3.00. For each vessel, 189 cases occur (3 loading conditions times 7 Froude numbers times $9 \lambda / \mathrm{L}$ values). As a result, Mediterranean fishing vessel database has a total of 2457 instances (13 hull forms times 3 loading conditions times 7 Froude numbers times $9 \lambda / \mathrm{L}$ values).
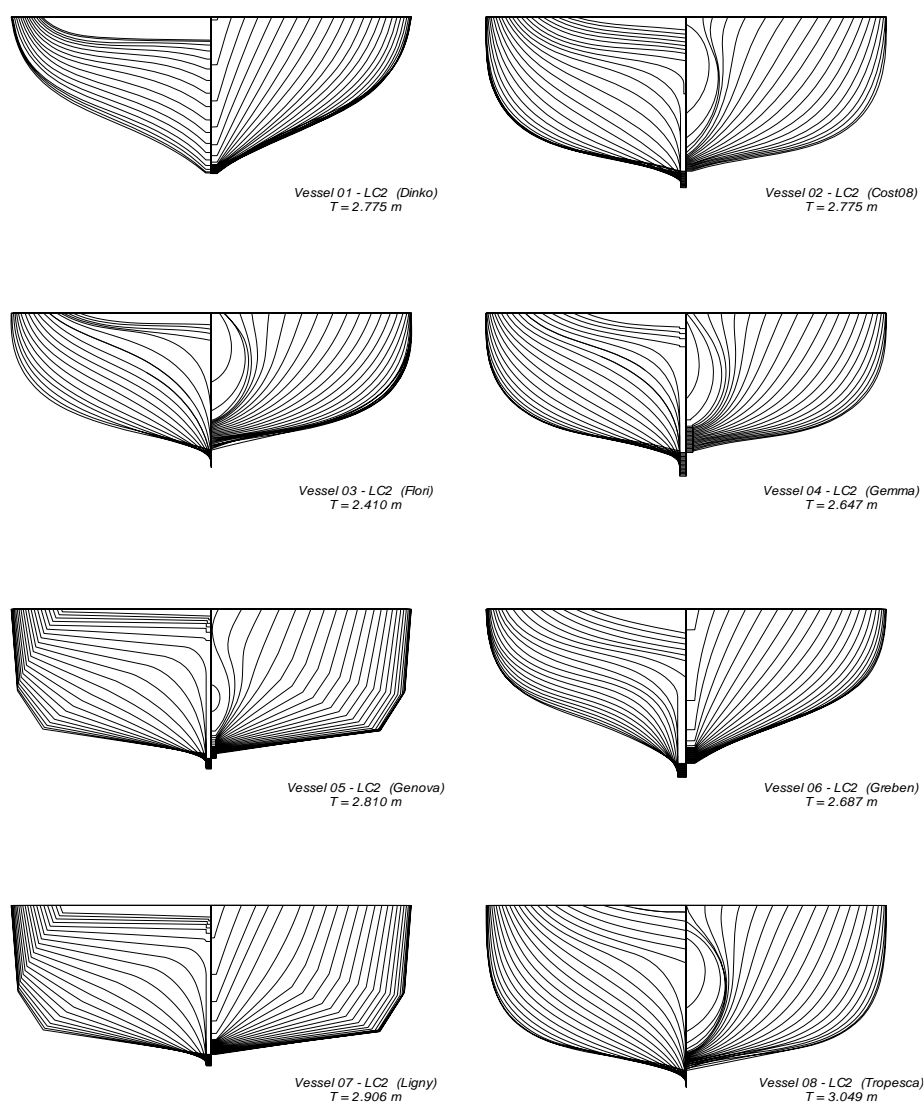
Determination of relational classification among hull form parameters and ship motions performance for a set of small vessels
Ayla Sayli

Ahmet Dursun Alkan, Merve Aydın

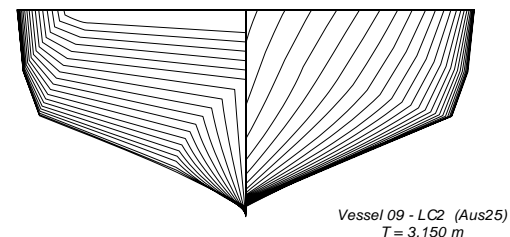

Vessel $09-\angle C 2$ (Aus25)
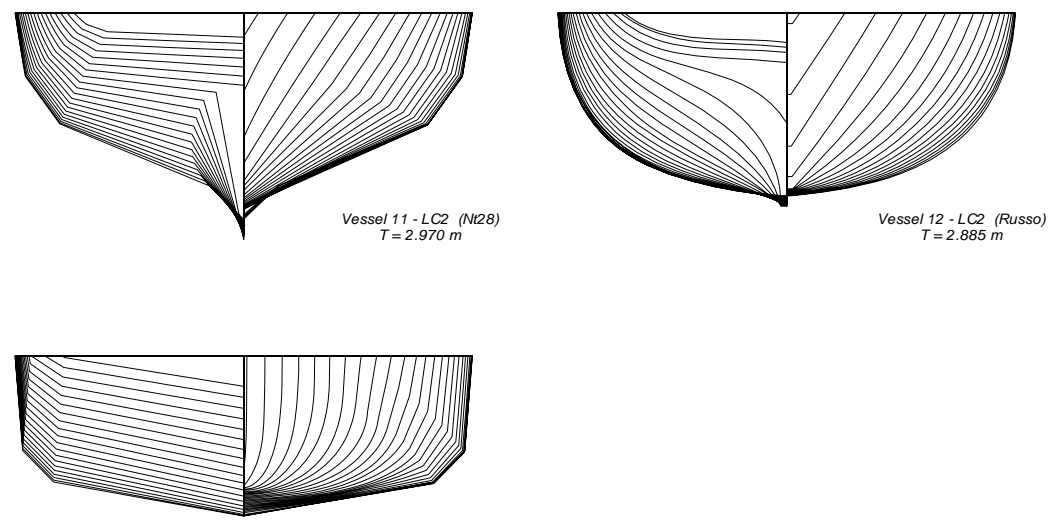

Vessel $13-L C 2$ (Ubcbig)

Fig. 3. Hull forms of the vessels.

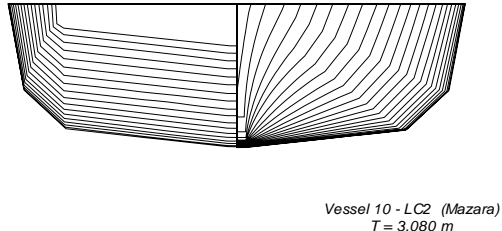

$10 \cdot-L C 2$ (Mazara)
$T=3.080 \mathrm{~m}$

Table 1 Hull form parameters.

\begin{tabular}{|c|c|c|c|c|c|c|c|c|c|c|c|c|}
\hline Vessel & $\begin{array}{c}L \\
(\mathrm{~m})\end{array}$ & $\begin{array}{c}L / B \\
(-) \\
\end{array}$ & $\begin{array}{c}B / T \\
(-)\end{array}$ & $\begin{array}{c}L / \nabla^{1 / 3} \\
(-)\end{array}$ & $\begin{array}{c}C_{W P} \\
(-)\end{array}$ & $\begin{array}{c}C_{V P} \\
(-)\end{array}$ & $\begin{array}{c}C_{W P A} \\
(-)\end{array}$ & $\begin{array}{c}C_{W P F} \\
(-)\end{array}$ & $\begin{array}{c}C_{V P A} \\
(-)\end{array}$ & $\begin{array}{c}C_{V P F} \\
(-)\end{array}$ & $\begin{array}{c}L C F / L \\
(-)\end{array}$ & $\begin{array}{c}L C B / L \\
(-)\end{array}$ \\
\hline V_011 & 21.38 & 3.171 & 2.582 & 3.955 & 0.857 & 0.490 & 0.965 & 0.621 & 0.513 & 0.583 & 0.392 & 0.463 \\
\hline V_012 & 21.38 & 3.171 & 2.458 & 3.827 & 0.874 & 0.505 & 0.979 & 0.635 & 0.535 & 0.589 & 0.393 & 0.456 \\
\hline V_013 & 21.38 & 3.171 & 2.846 & 4.234 & 0.807 & 0.468 & 0.909 & 0.591 & 0.479 & 0.570 & 0.400 & 0.479 \\
\hline V_021 & 25.74 & 3.677 & 2.646 & 4.200 & 0.841 & 0.574 & 0.846 & 0.663 & 0.608 & 0.670 & 0.406 & 0.488 \\
\hline V_022 & 25.74 & 3.677 & 2.541 & 4.103 & 0.864 & 0.576 & 0.871 & 0.673 & 0.613 & 0.701 & 0.399 & 0.482 \\
\hline V_023 & 25.74 & 3.677 & 2.769 & 4.312 & 0.796 & 0.587 & 0.804 & 0.654 & 0.611 & 0.696 & 0.426 & 0.494 \\
\hline V_031 & 25.00 & 3.472 & 3.158 & 4.216 & 0.832 & 0.610 & 0.834 & 0.698 & 0.635 & 0.689 & 0.436 & 0.494 \\
\hline V_032 & 25.00 & 3.472 & 2.988 & 4.091 & 0.853 & 0.617 & 0.868 & 0.703 & 0.638 & 0.701 & 0.427 & 0.488 \\
\hline V_033 & 25.00 & 3.472 & 3.398 & 4.386 & 0.770 & 0.630 & 0.744 & 0.690 & 0.675 & 0.674 & 0.468 & 0.499 \\
\hline V_041 & 26.35 & 3.513 & 2.914 & 4.144 & 0.813 & 0.621 & 0.852 & 0.666 & 0.626 & 0.715 & 0.427 & 0.489 \\
\hline V_042 & 26.35 & 3.513 & 2.833 & 4.083 & 0.823 & 0.625 & 0.868 & 0.668 & 0.628 & 0.720 & 0.423 & 0.486 \\
\hline V_043 & 26.35 & 3.513 & 3.158 & 4.327 & 0.771 & 0.624 & 0.789 & 0.659 & 0.635 & 0.698 & 0.447 & 0.497 \\
\hline V_051 & 25.00 & 3.125 & 2.835 & 3.692 & 0.875 & 0.628 & 0.882 & 0.668 & 0.710 & 0.757 & 0.397 & 0.472 \\
\hline V_052 & 25.00 & 3.125 & 2.752 & 3.634 & 0.890 & 0.629 & 0.890 & 0.674 & 0.719 & 0.763 & 0.393 & 0.468 \\
\hline V_053 & 25.00 & 3.125 & 3.000 & 3.802 & 0.819 & 0.651 & 0.800 & 0.658 & 0.753 & 0.760 & 0.423 & 0.477 \\
\hline V_061 & 20.50 & 2.941 & 2.766 & 3.852 & 0.804 & 0.521 & 0.845 & 0.559 & 0.511 & 0.614 & 0.435 & 0.492 \\
\hline V_062 & 20.50 & 2.941 & 2.585 & 3.691 & 0.834 & 0.533 & 0.879 & 0.574 & 0.530 & 0.622 & 0.429 & 0.484 \\
\hline V_063 & 20.50 & 2.941 & 3.066 & 4.117 & 0.742 & 0.512 & 0.769 & 0.536 & 0.495 & 0.597 & 0.451 & 0.503 \\
\hline V_071 & 25.00 & 3.125 & 2.835 & 3.631 & 0.898 & 0.644 & 0.891 & 0.690 & 0.719 & 0.746 & 0.398 & 0.467 \\
\hline V_072 & 25.00 & 3.125 & 2.753 & 3.576 & 0.903 & 0.651 & 0.894 & 0.696 & 0.732 & 0.747 & 0.398 & 0.463 \\
\hline V_073 & 25.00 & 3.125 & 3.001 & 3.739 & 0.860 & 0.652 & 0.852 & 0.679 & 0.723 & 0.743 & 0.413 & 0.473 \\
\hline V_081 & 27.25 & 3.733 & 2.547 & 4.118 & 0.782 & 0.650 & 0.799 & 0.669 & 0.661 & 0.747 & 0.440 & 0.501 \\
\hline V_082 & 27.25 & 3.733 & 2.394 & 3.989 & 0.818 & 0.642 & 0.836 & 0.679 & 0.657 & 0.750 & 0.426 & 0.495 \\
\hline V_083 & 27.25 & 3.733 & 2.700 & 4.243 & 0.753 & 0.654 & 0.746 & 0.661 & 0.674 & 0.740 & 0.452 & 0.507 \\
\hline V_091 & 21.00 & 2.770 & 2.627 & 3.514 & 0.861 & 0.540 & 0.844 & 0.672 & 0.515 & 0.652 & 0.424 & 0.481 \\
\hline V_092 & 21.00 & 2.770 & 2.406 & 3.332 & 0.887 & 0.563 & 0.881 & 0.697 & 0.556 & 0.663 & 0.424 & 0.472 \\
\hline V_093 & 21.00 & 2.770 & 2.756 & 3.619 & 0.831 & 0.537 & 0.816 & 0.660 & 0.572 & 0.643 & 0.433 & 0.486 \\
\hline
\end{tabular}




\begin{tabular}{|l|l|l|l|l|l|l|l|l|l|l|l|l|}
\hline V_101 & 30.80 & 2.962 & 3.870 & 4.061 & 0.766 & 0.662 & 0.873 & 0.544 & 0.718 & 0.695 & 0.388 & 0.424 \\
\hline V_102 & 30.80 & 2.962 & 3.402 & 3.811 & 0.783 & 0.688 & 0.884 & 0.567 & 0.759 & 0.688 & 0.392 & 0.418 \\
\hline V_103 & 30.80 & 2.962 & 4.132 & 4.199 & 0.756 & 0.648 & 0.862 & 0.533 & 0.700 & 0.689 & 0.386 & 0.428 \\
\hline V_111 & 20.00 & 3.061 & 2.633 & 3.967 & 0.799 & 0.495 & 0.734 & 0.666 & 0.495 & 0.509 & 0.428 & 0.486 \\
\hline V_112 & 20.00 & 3.061 & 2.455 & 3.787 & 0.824 & 0.514 & 0.754 & 0.691 & 0.527 & 0.520 & 0.430 & 0.478 \\
\hline V_113 & 20.00 & 3.061 & 2.901 & 4.239 & 0.738 & 0.484 & 0.667 & 0.636 & 0.474 & 0.487 & 0.447 & 0.497 \\
\hline V_121 & 27.30 & 4.015 & 2.729 & 4.275 & 0.884 & 0.636 & 0.831 & 0.784 & 0.663 & 0.651 & 0.447 & 0.485 \\
\hline V_122 & 27.30 & 4.015 & 2.484 & 4.072 & 0.915 & 0.648 & 0.866 & 0.806 & 0.679 & 0.663 & 0.444 & 0.480 \\
\hline V_123 & 27.30 & 4.015 & 2.941 & 4.447 & 0.841 & 0.642 & 0.785 & 0.765 & 0.665 & 0.642 & 0.461 & 0.490 \\
\hline V_131 & 28.00 & 3.060 & 3.386 & 3.825 & 0.854 & 0.663 & 0.903 & 0.699 & 0.658 & 0.770 & 0.428 & 0.488 \\
\hline V_132 & 28.00 & 3.060 & 2.995 & 3.599 & 0.885 & 0.680 & 0.939 & 0.707 & 0.685 & 0.788 & 0.416 & 0.477 \\
\hline V_133 & 28.00 & 3.060 & 3.704 & 4.003 & 0.823 & 0.657 & 0.859 & 0.694 & 0.650 & 0.755 & 0.442 & 0.496 \\
\hline Min & 20.00 & 2.770 & 2.394 & 3.332 & 0.738 & 0.468 & 0.667 & 0.533 & 0.474 & 0.487 & 0.386 & 0.418 \\
\hline Max & 30.80 & 4.015 & 4.132 & 4.447 & 0.915 & 0.688 & 0.979 & 0.806 & 0.759 & 0.788 & 0.468 & 0.507 \\
\hline
\end{tabular}

\section{K-MEANS ALGORITHM}

In general, the initial points of K-Mean algorithm are randomly chosen. In this study, choosing of the points is not randomly because it may not always give the clusters correctly (see subsection 3.1). The data set is divided $\mathrm{k}$ cluster. Then the middle point of each group is the center point of the cluster it belong to. The steps of the algorithm are given below:

Step 1. Calculate the Euclidean distance from each object to each cluster: Each object is assigned to the closest cluster. The Euclidean distance is calculated by Equation (3.1). $\mathrm{N}$ is number of attributes of data set.

$$
d(i, j)=\sqrt{\left|x_{i 1}-x_{j 1}\right|^{2}+\left|x_{i 2}-x_{j 2}\right|^{2}+\ldots+\left|x_{i N}-x_{j N}\right|^{2}}
$$

Step 2. Calculate the sum of squared error of clustering: The assignment mechanism of Kmeans algorithm allows all data to be in only one cluster. The Sum of Squared Error- SSE- is widely used determination of number of cluster and evaluation. The clustering which has the lowest value of SSE gives the best result. The sum of the square from objects to central points of the cluster can be calculated by Equation (3.2). The algorithm will try to determine the part $\mathrm{k}$ to reduce SSE [6].

$$
S S E=\sum_{i=1}^{k} \sum_{X \in C_{i}} d^{2}\left(M_{i}, X\right)
$$

Where $\mathrm{d}$ is the Euclidean distance, $\mathrm{M}$ is the mean vector, $\mathrm{X}$ is any instance of each cluster.

Step 3. Determine a new center point for each cluster: The mean vector is recalculated each time and members of a cluster can be changed.

Step 4. Repeat step 2, 3 and 4 until the members of clusters are not changed. 


\subsection{ESTIMATION OF THE TRUE K NUMBER OF CLUSTERS IN K-MEANS}

\section{ALGORITHM}

The performance of a clustering algorithm is affected by the chosen value of $\mathrm{k}$. Estimation of $\mathrm{k}$ is important for the correct clustering. K-means algorithm acts to try to find a minimum for SSE. The oldest method for determining the true number of clusters in a data set is inelegantly called the Elbow method [10].

\section{The steps of Elbow Method are in the following:}

Step 1. Apply K-means algorithm for different values of $\mathrm{k}$. The number of $\mathrm{k}$ can takes value of from 1 to the number of instances.

Step 2. Calculate SSE for each cluster and the total of SSE

Step 3. Plot line chart of the total of SSE each value of $k$.

Step 4. Choose a small value of $k$ that still has a low SSE.

\section{SOFTWARE APPLICATION}

In this study, we have implemented a in-house self-coded software application for Kmeans algorithm with the Elbow method and its interface is given in Fig. 4. During the implementation, every case is considered to allow for the user's selection and then the clustering can be triggered.

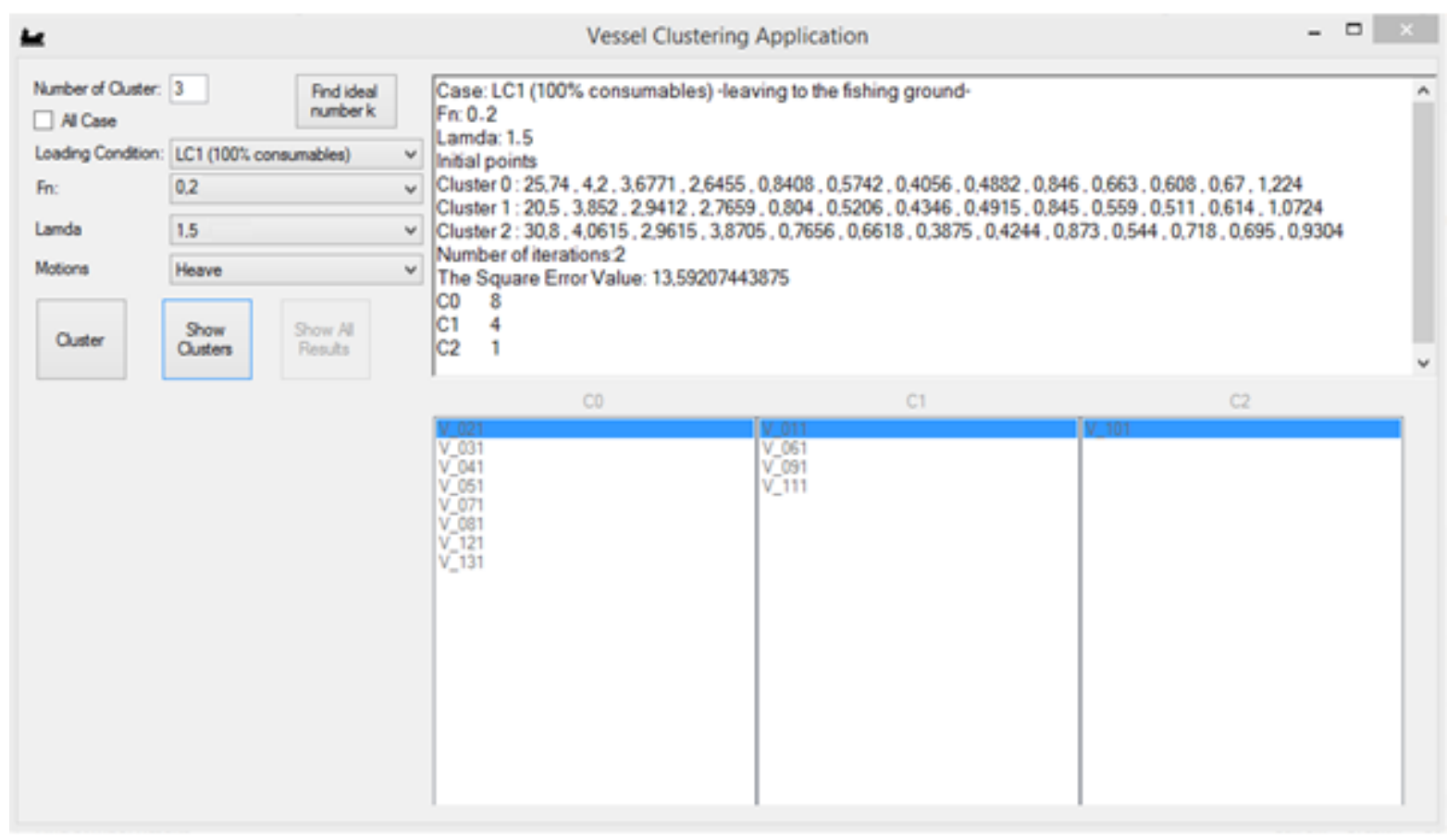

Fig. 4. Vessel Clustering Application's Interface. 
For instance, any specified case can be selected; for example Loading Condition as LC1 ( $100 \%$ consumables), Fn as $0.20, \lambda / \mathrm{L}$ as 1.50 and the motion as heave. During the clustering, before applying K-Means, we have to determine true number of $\mathrm{k}$ for the motion of heave by Elbow Method. After the estimation of the true value, the application can continue to cluster the vessels and finally gives the results for clusters.

\section{COMPUTATIONAL RESULTS}

The results are organised in two goals. The first goal in subsection 5.1 is to cluster the vessels by our application and the second in subsection 5.2 is to discuss these clusters about their outstanding consequents of clusters for seakeeping.

\subsection{VESSEL CLUSTERS}

As mentioned before that 189 cases occur in the Mediterranean fishing vessel database. The K-Means algorithm can be applied to each case or all. Furthermore, our database used by the algorithm is based on 12 hull form attributes which came from Table 1, the 13th attribute is used for heave, the 14th attribute for pitch and the 15th attribute for absolute vertical acceleration. According to the users' requests, any motion can be used for the clustering process in addition to all motions. In this subsection, we are going to give the results in two parts: in subsection 5.1.1 the determination of the true number of $\mathrm{k}$ is given and in subsection 5.1.2 the application of K-Means algorithm is shown.

\subsubsection{DETERMINATION OF THE TRUE NUMBER OF K}

The true value of $\mathrm{k}$ by Elbow method can be in the range of 1 and 13 for the database of Mediterranean Fishing Vessels. The total SSE can be different for each case. That's why, the total SSE is the average of SSE of each case. For each motion, line charts are shown in Fig. 5 and Fig. 6.

The line chart for all motions (Heave- Pitch-Vertical acceleration) is shown in Fig. 5. The total of SSE goes down rapidly the number of $\mathrm{k}$ from 1 to 2 , and from 2 to 3 . Then, it goes down slowly after the number of $\mathrm{k}$ is 3 . We reach the true number of $\mathrm{k}$ is 3 for all of motion.

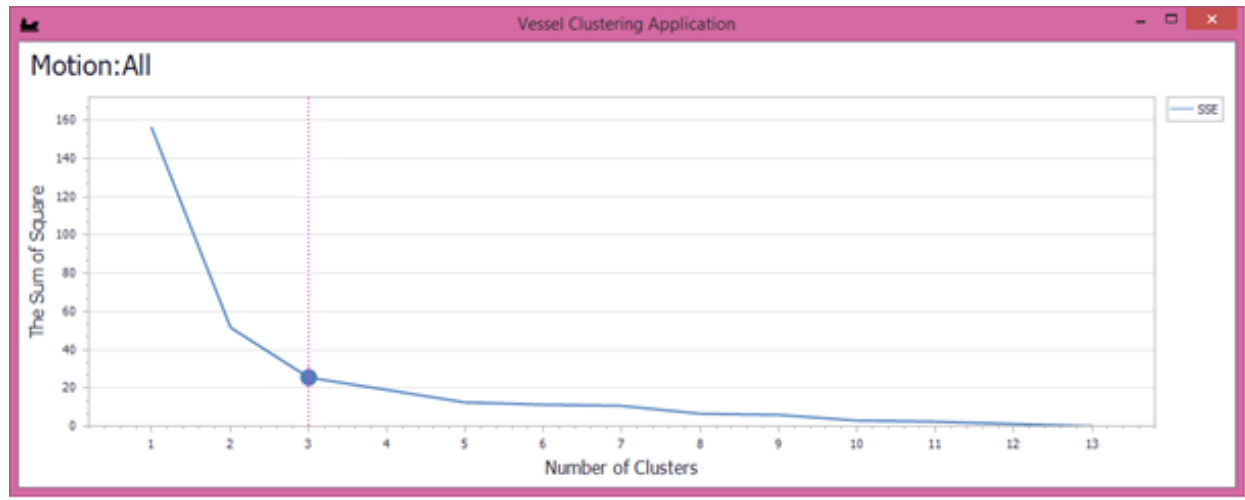

Fig. 5. The line chart of the true number of $\mathrm{k}$ for Heave- Pitch-Vertical acceleration.

The line chart for the heave motion only is shown in Fig.6. The total of SSE goes down rapidly until 3. After that, it goes down slowly. The true number of $\mathrm{k}$ is 3 for the motion. 


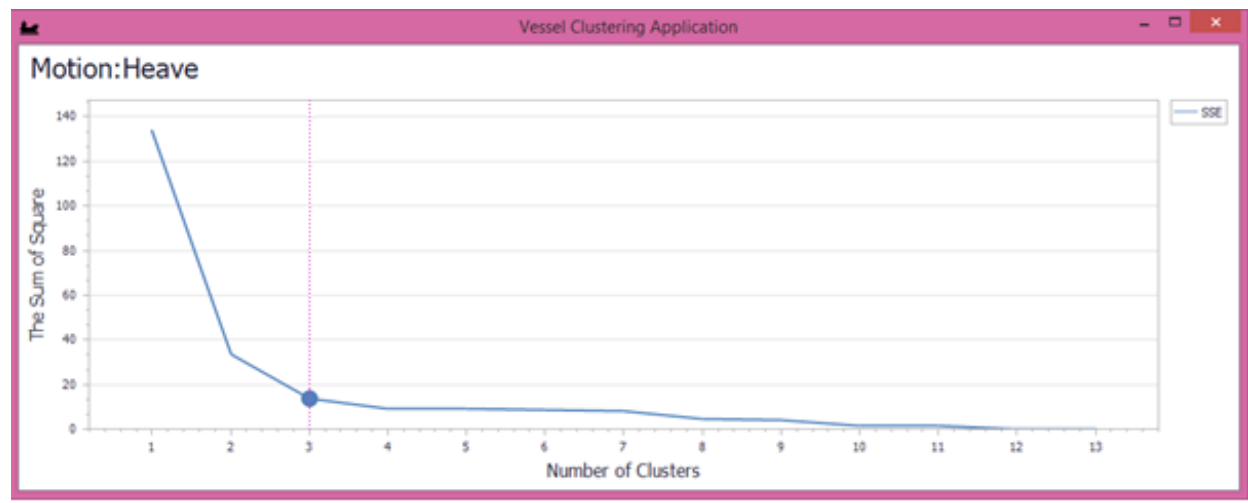

Fig. 6. The line chart of the true number of $\mathrm{k}$ for the heave motion.

The true numbers of $\mathrm{k}$ for pitch and vertical acceleration motions were obtained and they were also found similarly equaled to 3 . As a result, we reach the same true number of $\mathrm{k}$ for each motion and all motions for the Mediterranean fishing vessel data set. However this method may not show the true number clearly for different data sets but it was very obvious for the Mediterranean fishing vessels.

\subsubsection{APPLICATION OF K-MEANS ALGORITHM}

This application involves four tests to cluster the vessels. The first test in (a) is done for all motions, the second in (b) for heave, the third for pitch and the last for vertical accelaretion to find the vessel clusters based on similarity.

a) CLUSTERING FOR ALL MOTIONS: The results of clustering for all motions are displayed in Fig. 7. Vessel2, Vessel3, Vessel5, Vessel7, Vessel8, Vessel12 and Vessel13 belong to Cluster 0 (abbreviated as C0). But some case Vesse15, Vessel7, Vessel13 belong to different case. Vessel1, Vessel6, Vesse19 and Vessel11 belong clearly to Cluster 1 (C1). Vessel10 belongs to Cluster 2 (C2).

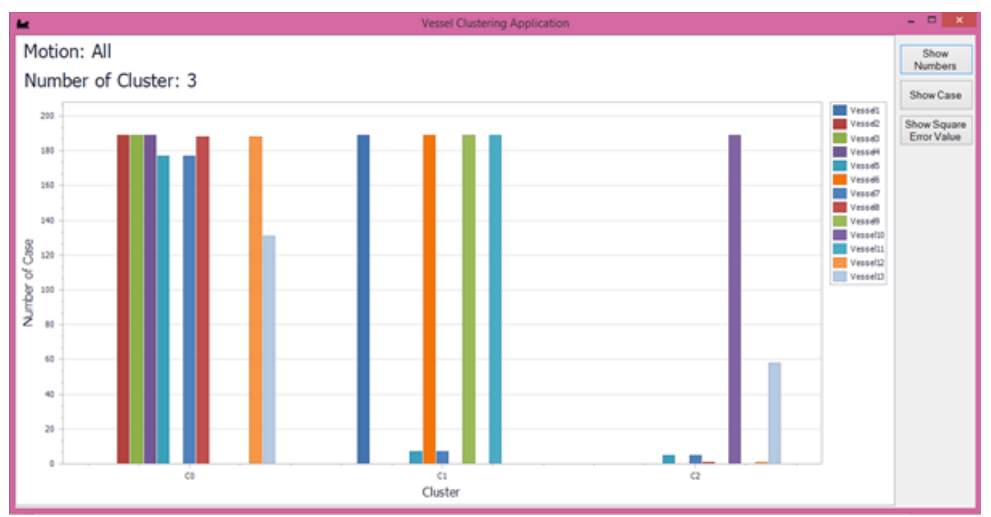

Fig. 7. Clusters for all of motions (Heave, Pitch, Vertical acceleration) with the true number of k as 3.

b) CLUSTERING FOR HEAVE : The results of clustering for the heave motion are shown in Fig. 8. Vessel2, Vessel3, Vessel5, Vessel7, Vessel8, Vessel12 and Vessel13 belong clearly to Cluster 0. Vessel1, Vessel6, Vessel9 and Vessel11 belong clearly to Cluster 1 and Vessel10 belongs to Cluster two. 


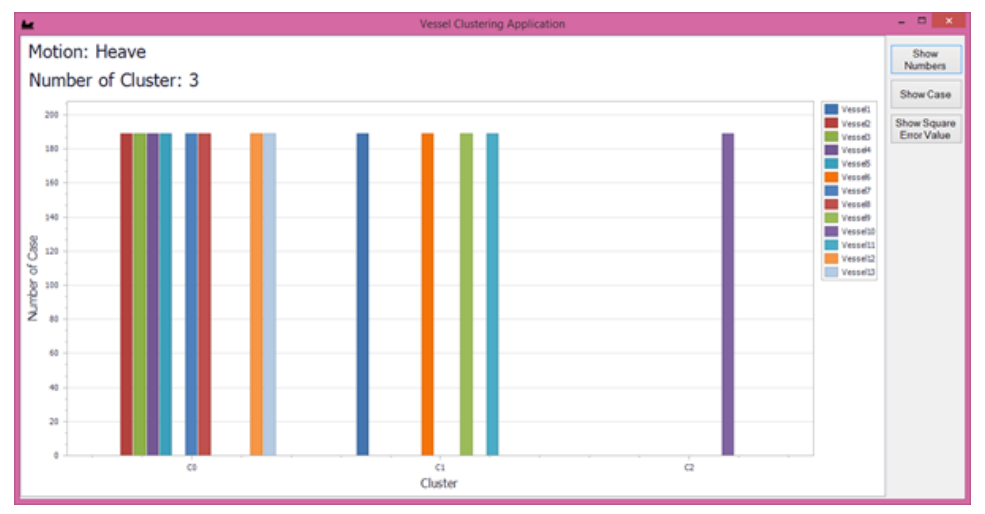

Fig. 8 Clusters for Heave motion only with the true number of $\mathrm{k}$ as 3 .

Last two tests were done for pitch and veritcal accelaration motions and the similar results were estimated. To generalise, results of the tests are summaried in Table 2 below:

Table 2. General Results of Clusters for all motions, each motion of heave, pitch and vertical acceleration.

\begin{tabular}{|l|c|c|c|c|c|c|c|c|c|c|c|c|c|}
\hline Motion & Vessel1 & Vessel2 & Vessel3 & Vessel4 & Vessel5 & Vessel6 & Vessel7 & Vessel8 & Vessel9 & Vessel10 & Vessel11 & Vessel12 & Vessel13 \\
\hline All Motions & $\mathrm{C} 1$ & $\mathrm{C} 0$ & $\mathrm{C} 0$ & $\mathrm{C} 0$ & $\mathrm{C} 0$ & $\mathrm{C} 1$ & $\mathrm{C} 0$ & $\mathrm{C} 0$ & $\mathrm{C} 1$ & $\mathrm{C} 2$ & $\mathrm{C} 1$ & $\mathrm{C} 0$ & $\mathrm{C} 0$ \\
\hline Heave & $\mathrm{C} 1$ & $\mathrm{C} 0$ & $\mathrm{C} 0$ & $\mathrm{C} 0$ & $\mathrm{C} 0$ & $\mathrm{C} 1$ & $\mathrm{C} 0$ & $\mathrm{C} 0$ & $\mathrm{C} 1$ & $\mathrm{C} 2$ & $\mathrm{C} 1$ & $\mathrm{C} 0$ & $\mathrm{C} 0$ \\
\hline Pitch & $\mathrm{C} 1$ & $\mathrm{C} 0$ & $\mathrm{C} 0$ & $\mathrm{C} 0$ & $\mathrm{C} 0$ & $\mathrm{C} 1$ & $\mathrm{C} 0$ & $\mathrm{C} 0$ & $\mathrm{C} 1$ & $\mathrm{C} 2$ & $\mathrm{C} 1$ & $\mathrm{C} 0$ & $\mathrm{C} 0$ \\
\hline Vertical Acceleration & $\mathrm{C} 1$ & $\mathrm{C} 0$ & $\mathrm{C} 0$ & $\mathrm{C} 0$ & $\mathrm{C} 0$ & $\mathrm{C} 1$ & $\mathrm{C} 0$ & $\mathrm{C} 0$ & $\mathrm{C} 1$ & $\mathrm{C} 2$ & $\mathrm{C} 1$ & $\mathrm{C} 0$ & $\mathrm{C} 0$ \\
\hline
\end{tabular}

\subsection{OUTSTANDING CONSEQUENTS OF CLUSTERS FOR SEAKEEPING}

Ship motions or seakeeping performance of ships in various conditions of real seaway environment are crucial problems that the following objectives are required to reach an optimized ship design based on seakeeping.

1. Minimize amplitudes of vessel motions, velocity and accelerations

2. Minimize frequency of occurrences of seakeeping phenomena such as deck wetness, slamming, local accelerations

3. Optimal hull form, load distribution and speed of advance that enable not stiff but tender and/or acceptable oscillating motions such as heave, pitch and vertical acceleration motions.

In order to reach and satisfy these objectives, the ship designer needs to have a detailed information among the data of hull form parameters and ship motion performance. The design principle is that the rational consideration of potential seakeeping behavior from the beginning of the design process in real leads the design economical. The beginning of the design process is so-called conceptual design stage, as generally accepted, requires simplicity in use while assuring sufficient accuracy in prediction.

Cluster 0 in Table 3 contains eight vessels and three loading conditions for each, totally 24 hull variants. On the other hand, Cluster 1 in Table 4 has four vessels, those are Vessel 01, Vessel 06, Vessel 09 and Vessel 11, and the three loading conditions of each, 12 hull variants of these four vessels. It is worthwhile to underline that the hull variants remained also in the same cluster because of the parametric relation of hull form variables. 
Table 3. Cluster 0 .

\begin{tabular}{llll}
\hline Vessel 02 & Vessel 03 & Vessel 04 & Vessel 05 \\
\hline V_021, V_022, V_023 & V_031, V_032, V_033 & V_041, V_042, V_043 & V_051, V_052, V_053 \\
\hline Vessel 07 & Vessel 08 & Vessel 012 & Vessel 013 \\
\hline V_071, V_072, V_073 & V_081, V_082, V_083 & V_121, V_122, V_123 & V_131, V_132, V_133 \\
\hline
\end{tabular}

Table 4. Cluster 1.

\begin{tabular}{llll}
\hline Vessel 01 & Vessel 06 & Vessel 09 & Vessel 11 \\
\hline V_011, V_012, V_013 & V_061, V_062, V_063 & V_091, V_092, V_093 & V_111, V_112, V_113 \\
\hline
\end{tabular}

The correlation analysis among the vessels in Cluster 1 (Vessel 01, 06, 09 and 11) for heave motion has showed a highly close approximation compared to the output of Simple Model $[8,9]$ which was obtained by the correlation analysis of all 39 vessel variants, for 13 vessels with three loading conditions. In Simple Model, the ship motions were represented in function of hull form parameters of length to beam ratio, beam to draught ratio, length to volume ratio $\left(\mathrm{LPP}_{\mathrm{PP}} / \mathrm{B}, \mathrm{B} / \mathrm{T}, \mathrm{L} / \nabla^{1 / 3}\right)$, speed to length ratio (Froude number, Fn) and wave length to ship length ratio $(\lambda / L)$. It should be noted that while the Simple Model used in our previous study [8] was applied to the database of all vessels in Table 1, here we applied the same model to two different Clusters, Cluster 0 and Cluster 1. A detailed comparison study has been carried for several vessels in order to show the approximation level of Cluster 1 that was represented by a database of 13 vessels. Our computations have shown that Cluster 1 gives relatively higher correlation level for all motions. Fig. 9 shows the correlation values for both Simple Model in our previous study [8] and the Cluster 1 . The computed and approximated values of the transfer functions of heave, pitch and vertical acceleration for the vessels that reflect the general accuracy of the Cluster 1 with respect to computed responses shown in Fig. 10-12. However, the approximation for vertical acceleration is relatively far from the level of approximation obtained for other motion responses of heave and pitch. The figures showed that a group of twelve vessels of Cluster 1 in the vessel database is able to predict ship transfer functions in an acceptable level by means of $\mathrm{L}, \mathrm{B}, \mathrm{T}, \nabla, \mathrm{Fn}$ and $\lambda / \mathrm{L}$ comparing with the computed data that used whole geometry of the vessels. It can be concluded that a meta-model using the database defined by Cluster 1 is capable to offer satisfying predictions for conceptual design purposes. Cluster 0 is also capable to give almost the same success of the approximation as Cluster 1. Fig. 13 shows a typical approximation of Cluster 0 for the heave motion in comparison with Simple Model. 
Determination of relational classification among hull form parameters and ship motions performance for a set of small vessels
Ayla Sayli

Ahmet Dursun Alkan, Merve Aydın

- SM [1] a Cluster 1

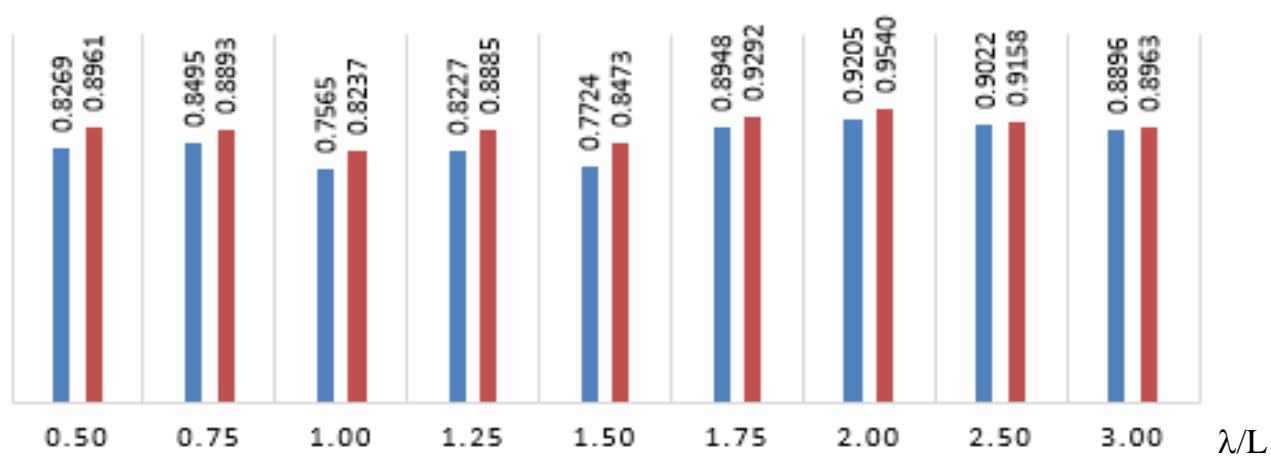

Fig. 9. Correlations $\left(\mathrm{R}^{2}\right)$ for Simple Model [8] and Cluster 1 for heave motion for each $\lambda / \mathrm{L}$.

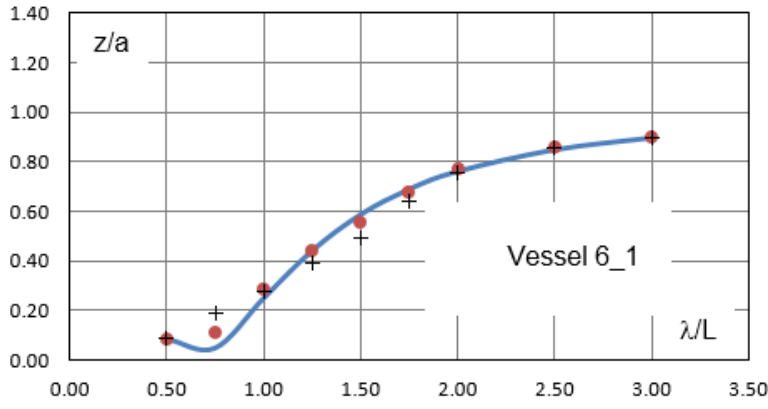

- Computed $+\mathrm{SM} \bullet \mathrm{C} 1 @ \mathrm{Fn}=0$

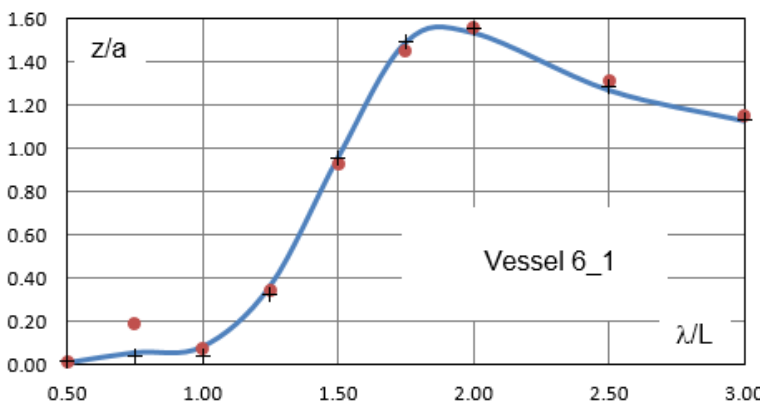

- Computed + SM・ C1 @ Fn=0.30

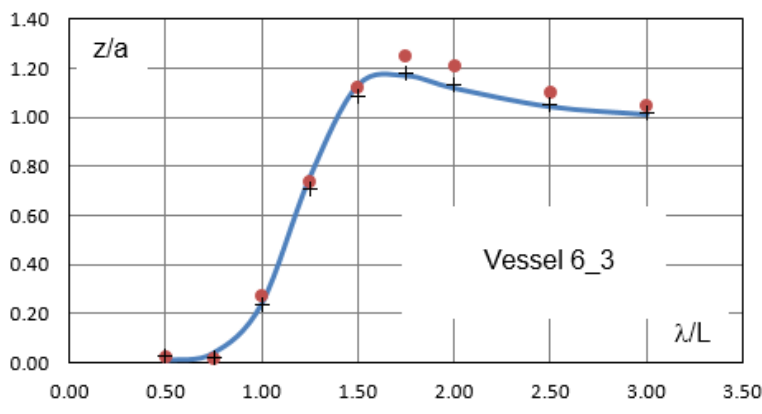

- Computed + SM・C1@ Fn=0.20

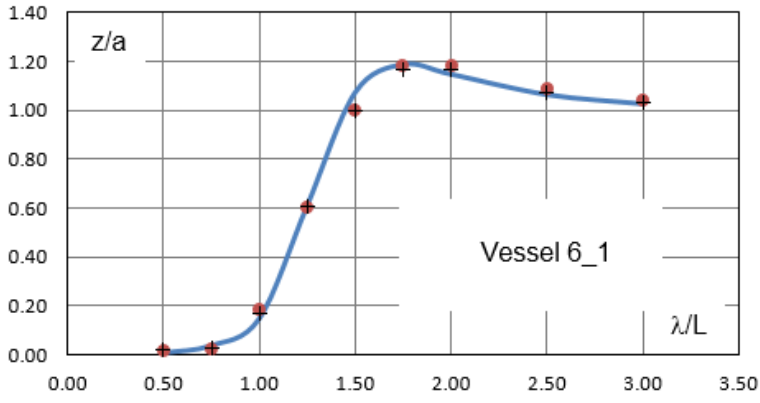

- Computed + SM・ C1@ Fn=0.20

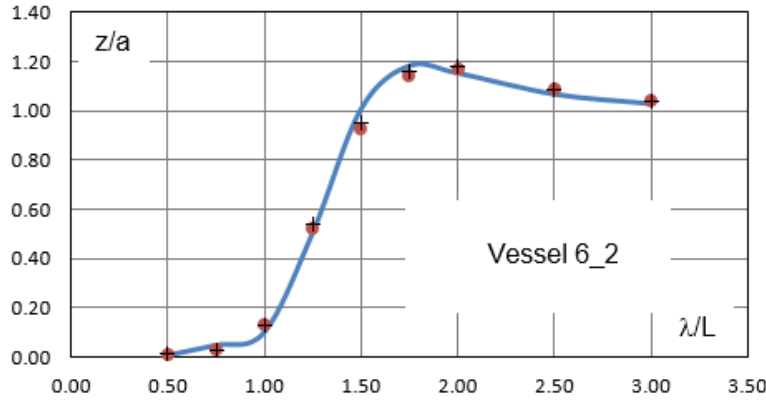

- Computed $+\mathrm{SM} \bullet \mathrm{C} 1 @ \mathrm{Fn}=0.20$

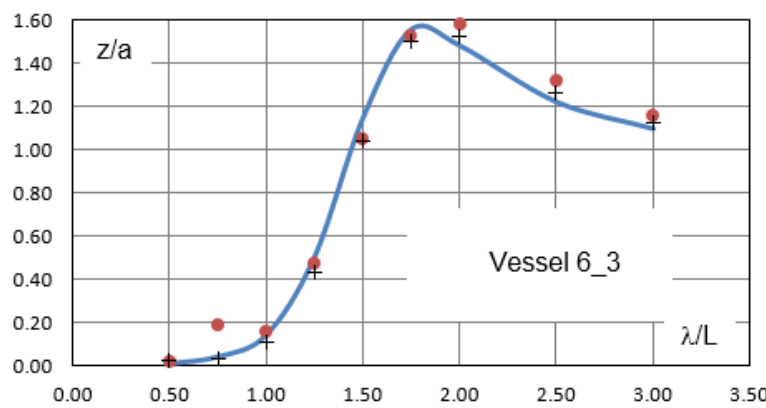

- Computed + SM・C1@ Fn=0.30

Fig. 10. Heave motion (z/a) RAOs of Vessel 061, Vessel 062 and Vessel 061 at Froude numbers 0.0, 0.20 and 0.30, Legend: Continuous line: Strip theory calculation, SM: Simple Model [8], C1: "Cluster 1". 
Determination of relational classification among hull form parameters and ship motions performance for a set of small vessels
Ayla Sayli

Ahmet Dursun Alkan, Merve Aydın

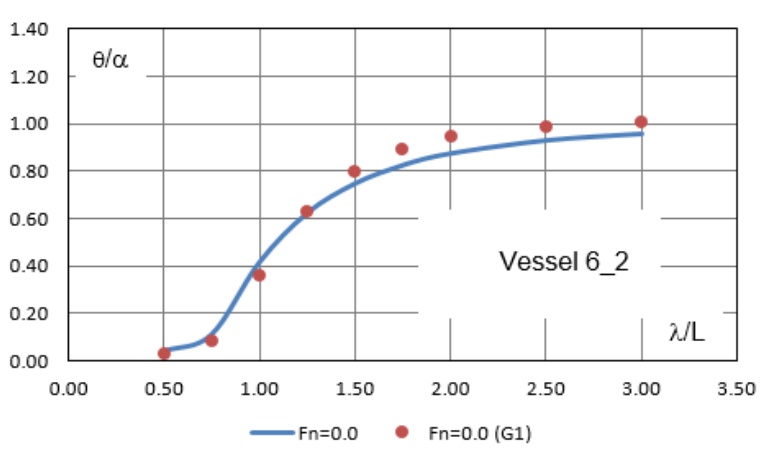

-Computed・C1@ $@$ Fn=0.00

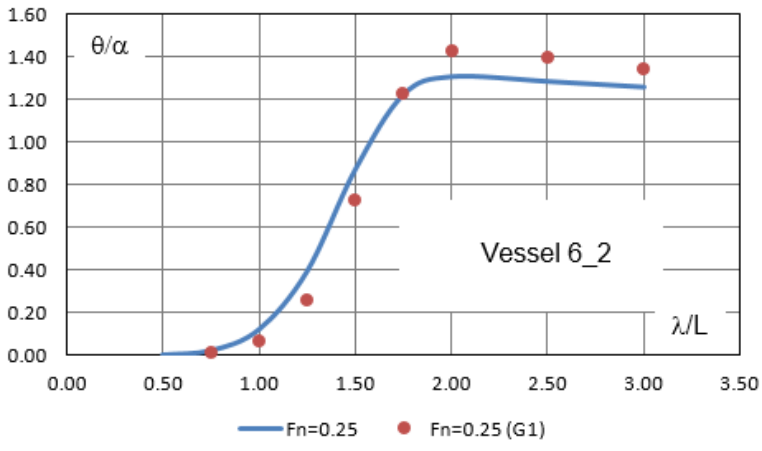

- Computed・C1@ $@ \mathrm{Fn}=0.25$

Fig. 11. Pitch motion $(\theta / \alpha)$ RAOs of Vessel 062 at Froude numbers 0.0 and 0.25 , Cluster 1 vessels.

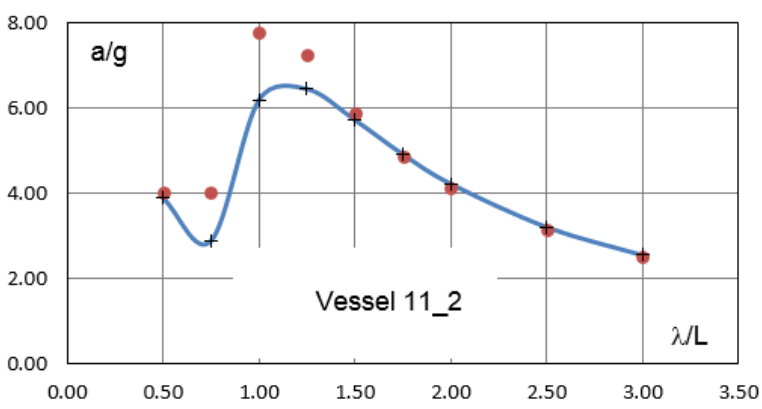

- Computed + SM・C1@ Fn=0.00

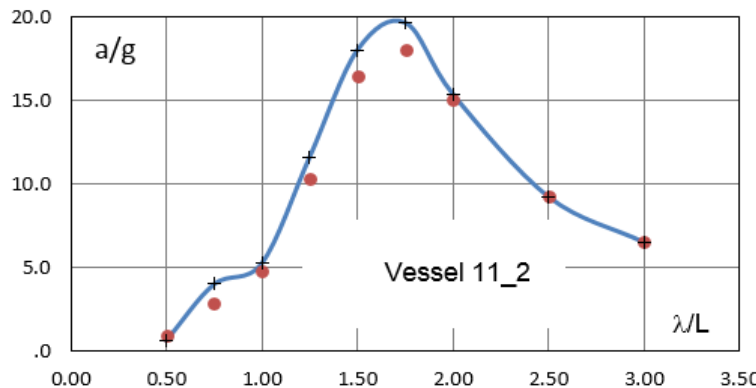

-Computed + SM・C1 @ Fn=0.30

Fig. 12. Vertical acceleration (a/g) RAOs of Vessel 112 at Froude numbers 0.0 and 0.30 Simple Model Cluster 1.

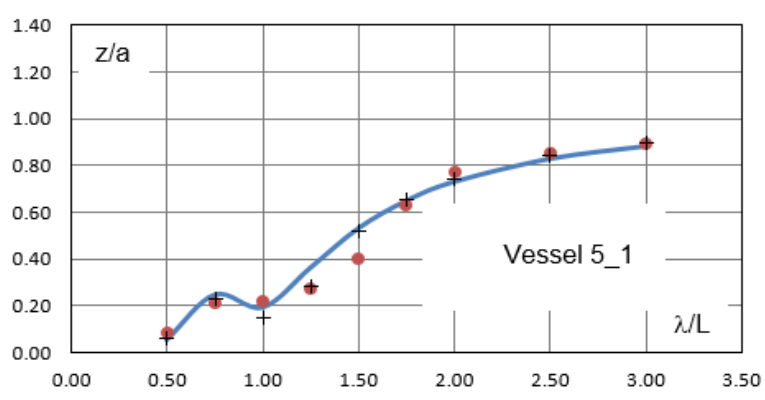

- Computed + SM・C0@ Fn=0.00

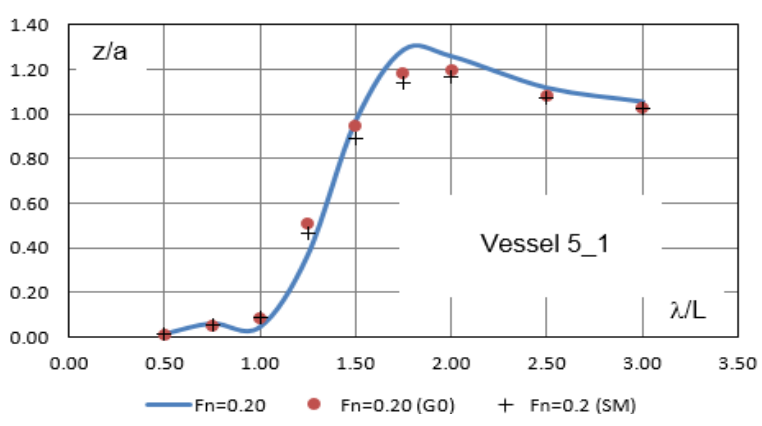

- Computed + SM・C0 @ Fn=0.20

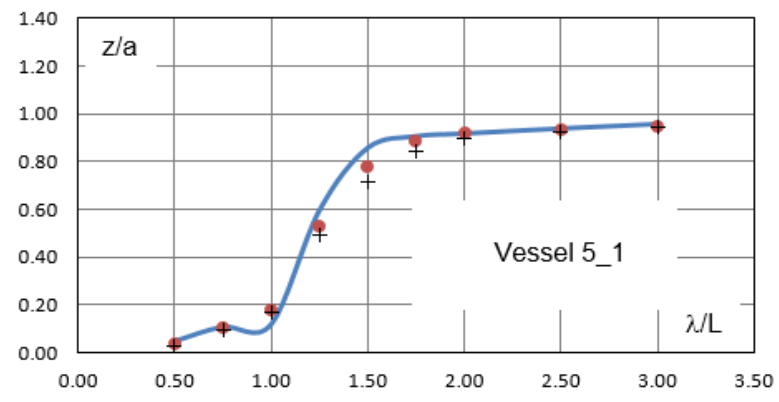

- Computed $+\mathrm{SM} \bullet \mathrm{C} 0 @ \mathrm{Fn}=0.10$

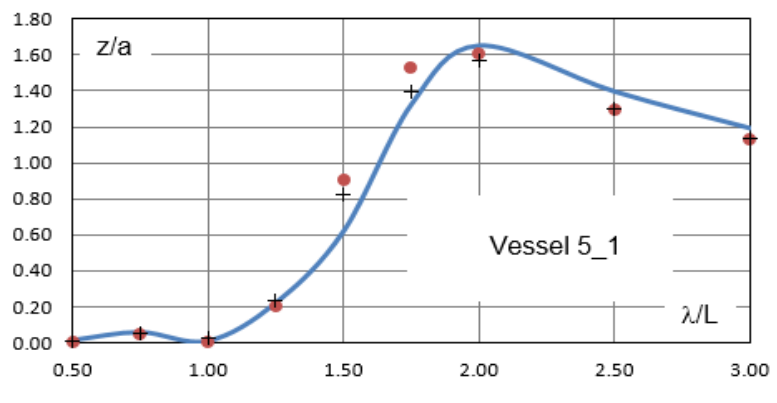

—Computed + SM・ C0 @ Fn=0.30

Fig. 13. Heave motion (z/a) RAOs of Vessel 051 at Froude numbers 0.0, 0.10, 0.20 and 0.30., Continuous line: Strip theory calculation, SM: Simple Model, C0: Cluster 0. 
The clustered databases are used to model ship motions also with more hull form parameters, for this purpose, Enhanced 2 Model in our past study in [8] was taken into consideration. Enhanced 2 Model is a further extension of Simple Model parameters with water plane area ratio and prismatic coefficients for aft and forward parts of the hull body, those are $\mathrm{L}_{\mathrm{PP}} / \mathrm{B}, \mathrm{B} / \mathrm{T}$, $\mathrm{L} / \nabla^{1 / 3}, \mathrm{C}_{\mathrm{WPA}}, \mathrm{C}_{\mathrm{WPF}}, \mathrm{C}_{\mathrm{VPA}}, \mathrm{C}_{\mathrm{VPF}}$, respectively. The calculations based on the databases of Cluster 1 and the Cluster 0 do not make any significant change in the approximation scored in [8].

It is noteworthy to comment that though Vessel 10 was remained alone in Cluster 2, the hull can be evaluated in one of Clusters based on the experience and tuition of ship designer.

\section{CONCLUSION}

As a conversion tool from data into knowledge, cluster analysis based on data mining can be applied to ship hull forms to determine relational classification of a hull geometry parameters and performance characteristics defined by transfer functions (RAO) of heave and pitch motions and of absolute vertical acceleration. Roll motion and MSI index which are different topics are also under the consideration of the authors for further researches. Our analysis defined three clusters for conceptual design purposes and cluster analysis is a useful tool for ship designers, especially she/he has a large number of hull and performance data, who can classify alternative ship designs based on their relational data composed of hull geometry and performance measure(s). The cluster analysis concluded that though a vessel has three loading conditions as design variants remained in the same cluster without detaching from their main hull, for example Vessel X_01, Vessel X_02, Vessel X_03 remained in the same cluster. We propose that the cluster analysis is useful during conceptual design tasks where the designer tries to set up a reliable meta-model and thus to perform decision based optimization studies [5], keeping in the mind that a sufficient number of comparable statistical data are needed to allow common principles of the statistics. In such problems, cluster analysis will be useful to seek and judge significant set of parameters influencing various outputs of interest that enables the ship designer to develop robust and innovative solutions based on scientific approaches. 
Determination of relational classification among hull form parameters and ship motions performance for a set of small vessels
Ayla Sayli

Ahmet Dursun Alkan, Merve Aydın

\section{REFERENCES}

[1] Trincas, G. (2007), Ship Design Process - A Rational Approach, Lecture Notes, University of Trieste, Trieste.

[2] Papanikolaou, A., 2014, Ship Design - Methodologies of Preliminary Design, Springer press, ISBN: 978-94017-8750-5.

[3] Chen, D., Yao, Z. (2014), Analysis on Ship Equipment Consumption Data Based on Data Mining, Advanced Materials Research, Vol. 846-847, pp. 1141-1144, http://dx.doi.org/10.4028/www.scientific.net/AMR.846$\underline{847.1141 .}$.

[4] Li C., Zhao R., Xiang Y., Xu S. (2008), Data Mining Approach for Ship Virtual Assembly based on Rough Set Theory, 2008 International Conference on Computational Intelligence and Security, CIS 2008, Suzhou, China. http://dx.doi.org/10.1109/CIS.2008.126.

[5] Mosavi, A. (2010), Multiple Criteria Decision-Making Preprocessing Using Data Mining Tools, IJCSI International Journal of Computer Science Issues, Vol. 7, Issue 2, No 1, pp. 26-34.

[6] Isik, M. and Camurcu, A. (2007), K-Means, K-Medoids ve Bulanık C-Means Algoritmalarının Uygulamalı Olarak Performanslarının Tespiti, İstanbul Ticaret Üniversitesi Fen Bilimleri Dergisi, Yıl: 6 Sayı: 11, Bahar 2007/1, pp. 31-45.

[7] Kodinariyal, T. and Makwana, P. (2013), Review on Determining Number of Cluster in K-Means Clustering, International Journal of Advance Research in Computer Science and Management Studies Volume 1, Issue 6, pp. 90-95.

[8] Sayli, A., Alkan, A. D., Nabergoj, R. and Uysal, A. Ö. (2007), Seakeeping Assessment of Fishing Vessels in Conceptual Design Stage. Ocean Engineering, 34(5), pp.724-738. http://dx.doi.org/10.1016/j.oceaneng.2006.05.003.

[9] Sayli, A., Alkan, A. D. and Ganiler, O. (2010). Nonlinear meta-models for conceptual seakeeping design of fishing vessels. International Journal of Ocean Engineering, 37(8), pp. 730-741. http://dx.doi.org/10.1016/j.oceaneng.2010.02.005.

[10] Andrew Ng (2012), Clustering with the K-Means Algorithm, Machine Learning.

Submitted: $\quad$ 06.06.2016. $\quad$ Ayla Sayli, corresponding author, sayli@yildiz.edu.tr

Department of Mathematical Engineering, Yıldız Technical University (YTU),

Accepted: $\quad$ 07.08.2016. Davutpasa Campus 34210, Istanbul, Turkey.

Ahmet Dursun Alkan, alkanad@yildiz.edu.tr

Department of Naval Arch. and Marine Engineering, YTU, Istanbul, Turkey.

Merve Aydın, mrvaydin50@gmail.com

Department of Mathematical Engineering, YTU, Davutpasa Campus 34210,

Istanbul, Turkey. 